\title{
ANALYSIS OF THERMAL COMFORT IN AN INTELLIGENT BUILDING
}

\author{
Grzegorz MAJEWSKI ${ }^{1,{ }^{*},}$, Marek TELEJKO ${ }^{1}$, Łukasz J. ORMAN ${ }^{1}$ \\ ${ }^{1}$ Kielce University of Technology, al. 1000-lecia P. P. 7, 25-314 Kielce, Poland \\ corresponding author: majewskigrzegorz@wp.pl
}

\begin{abstract}
Analysis of thermal comfort in the ENERGIS Building, an intelligent building in the campus of the Kielce University of Technology, Poland is the focus of this paper. For this purpose, air temperature, air relative humidity, air flow rate and carbon dioxide concentration were measured and the mean radiant temperature was determined. Thermal sensations of the students occupying the rooms of the building were evaluated with the use of a questionnaire. The students used a seven-point scale of thermal comfort. The microclimate measurement results were used to determine the Predicted Mean Vote and the Predicted Percentaae Dissatisfied indices.
\end{abstract}

\section{Keywords:}

Thermal comfort; Intelligent building; Air quality; Thermal sensation indices of human response.

\section{Introduction}

Every room occupied by people should have a microclimate that satisfies the thermal comfort of its occupants. Thermal comfort was first studied in the 20th century, when it was possible to control microclimate in buildings. This would not have been possible without the development of thermodynamics in the 19th century, which markedly contributed to the growth of thermal control technology. One of the first scientists to study thermal comfort was Bedford, who in 1936 proposed a seven-point scale of thermal sensations [1]. Other researchers of that time were Winslow, Herrington and Gagge [2]. In the sixties and seventies of the 20th century, L. O. Fanger published the thermal comfort equation and PMV (Predicted Mean Vote) and PPD (Predicted Percentage Dissatisfied) indices [3, 4]. These indices continue to apply as recommended by, for example, PN-EN ISO 7730 [5].

The current standards defining the mean vote (PMV) and the percentage of dissatisfied occupants (PPD) include the European standard PN-EN 15251 [6] and the American ASHRAE Standard 55-2013 [7]. Variable parameters of thermal comfort include air temperature and humidity, relative air flow rate, mean radiant temperature, clothing insulation and physical activity level. The main source of information on thermal comfort of people staying in different thermal environments are the assessments provided by them. The microenvironment friendly to humans should be adjustable, so that a person could describe it as not too warm or too cool, or in other words, comfortably warm or cool [8].

In rooms, thermal comfort is ensured when [9]:

a) the average temperature of the surrounding internal walls is equal to, or close to, the indoor room temperature;

b) in winter, air temperature is $20 \div 22{ }^{\circ} \mathrm{C}$; in summer, however, indoor temperature should be closer to the outdoor temperature, that shorter user stays on average in a given room. Summer indoor temperature should be $23 \div 25{ }^{\circ} \mathrm{C}$, in industrial spaces, the permitted temperature in summer is $28^{\circ} \mathrm{C}$;

c) air relative humidity is in the range $30 \div 70 \%$ (with $40 \div 60 \%$ being the optimum values), and the rate of change in relative humidity does not exceed $20 \%$ an hour;

d) air velocity does not exceed the predicted temperature-dependent values.

Compared with traditional buildings, indoor temperature in intelligent buildings can be controlled with great accuracy thus assuring thermal comfort of their occupants. The BMS of the ENERGIS building records a number of parameters, including air temperature in the rooms. Changes in this parameter over time may be used to draw conclusions on the quality of control in the building, and also increase the comfort of the users [10]. 
This paper describes the study of thermal comfort in seminar rooms of the university building. The real thermal sensation experienced by the occupants at seated positions was compared with the PMV (Predicted Mean Vote) and PPD (Predicted Percentage Dissatisfied) indices.

\section{Methods}

The tests were carried out in the intelligent building, ENERGIS, housing the Faculty of Environmental, Geomatic, and Energy Engineering at the Kielce University of Technology. The air temperature and relative humidity, as well as the carbon dioxide concentration were measured with an air quality monitor. The air movement velocity was measured with an anemometer, and a pyrometer was used to find the temperature of the internal walls surrounding the rooms. The measurement results were recorded every five minutes. To assess the thermal comfort of the room's occupants, an anonymous survey was performed. The students-respondents assessed their thermal sensations on a seven-point scale. A total of 114 students occupying three classrooms participated in the survey. During Test 1 and Test 2, the questionnaires were filled out at the beginning and at the end of the class. In Test 3, the students recorded their thermal sensations only once, at the end of the class. The tests were performed in a summer time. Test 1 was carried out in the classroom located on the west side, with a net area of $104.38 \mathrm{~m}^{2}$ on 2 July 2016 between 10:15 and 12:10. Test 2 was performed in the same room on 4 July 2016 between 08:05 and 09:45. Test 3 was performed in the classroom with the windows on the east and west side, of $458.86 \mathrm{~m}^{2}$ net area on 5 July 2016 between 10:30 and 11:15. Mechanical ventilation and air conditioning were on during the tests.

\section{Test results in comparison to existing models}

Table 1 summarizes the microclimate measurement results. From the questionnaire data, it was established that directly prior to and during the classes, the metabolic rate of all the respondents was 1.2 met $\left(70 \mathrm{~W} / \mathrm{m}^{2}\right)$ and their clothing insulation was $I_{c l}=0.50 \mathrm{clo}\left(0.080 \mathrm{~m}^{2} \mathrm{KW}\right)$. The carbon dioxide concentration recorded in Test 3 was noticeably higher than in Test 2 and Test 1 due to a larger number of respondents occupying the room. Indoor air temperatures at the beginning of the tests were higher than those at the end of the tests due to switching on the AC during the class. The air temperature at the beginning of the class was recorded prior to switching on the air conditioner.

Table 1: Summary of microclimate parameters in three university classrooms.

\begin{tabular}{|c|c|c|c|c|c|}
\hline $\begin{array}{l}\text { At the beginning } \\
\text { of class/ } \\
\text { At the end of class }\end{array}$ & $\begin{array}{c}\text { Outdoor } \\
\text { temperature } \\
{\left[{ }^{\circ} \mathrm{C}\right]}\end{array}$ & $\begin{array}{c}\text { Indoor } \\
\text { temperature } \\
{\left[{ }^{\circ} \mathrm{C}\right]}\end{array}$ & $\begin{array}{c}\text { Indoor } \\
\text { relative } \\
\text { humidity } \\
{[\%]}\end{array}$ & $\begin{array}{c}\text { Indoor } \\
\text { air flow rate } \\
{[\mathrm{m} / \mathrm{s}]}\end{array}$ & $\begin{array}{l}\text { Indoor carbon } \\
\text { dioxide } \\
\text { concentration } \\
\text { [ppm] }\end{array}$ \\
\hline \multicolumn{6}{|c|}{ TEST NO 1 (Classroom 1 with an area of $104.38 \mathrm{~m}^{2}$ ) } \\
\hline $\begin{array}{c}\text { At the beginning } \\
\text { of class }\end{array}$ & 32.0 & 27.3 & 48.5 & 0.08 & 586 \\
\hline $\begin{array}{l}\text { At the end } \\
\text { of class }\end{array}$ & 32.0 & 26.8 & 45.7 & 0.06 & 715 \\
\hline \multicolumn{6}{|c|}{ TEST NO 2 (Classroom 2 with an area of $104.38 \mathrm{~m}^{2}$ ) } \\
\hline $\begin{array}{c}\text { At the beginning } \\
\text { of class }\end{array}$ & 16.0 & 28.2 & 45.7 & 0.06 & 517 \\
\hline $\begin{array}{l}\text { At the end } \\
\text { of class }\end{array}$ & 16.0 & 28.0 & 45.5 & 0.08 & 651 \\
\hline \multicolumn{6}{|c|}{ TEST NO 3 (Classroom 3 with an area of $458.86 \mathrm{~m}^{2}$ ) } \\
\hline $\begin{array}{l}\text { At the beginning } \\
\text { of class }\end{array}$ & 25.0 & 27.9 & 48.4 & 0.11 & 1904 \\
\hline $\begin{array}{l}\text { At the end } \\
\text { of class }\end{array}$ & 25.0 & 26.1 & 48.4 & 0.13 & 2198 \\
\hline
\end{tabular}

Fig. 1 shows real mean perception of the students at the beginning and at the end of the classes. Their assessments vary with the test time. In Test 1 after a minor temperature loss, thermal sensation increased slightly at the end of classes, whereas in Test 2, after the minor temperature loss, the average perception decreased. 


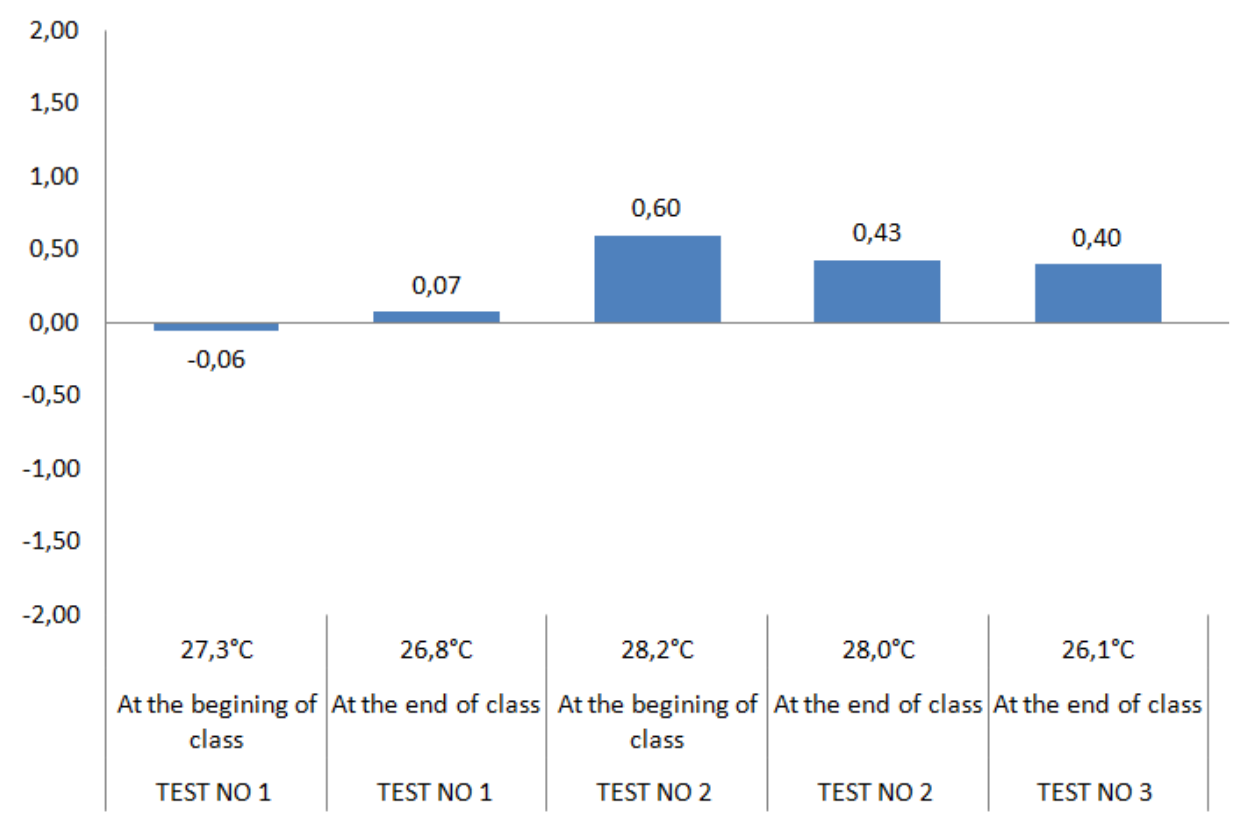

Actual average assessment of thermal sensation

Fig. 1: Real average thermal sensations of the respondent at the beginning and at the end of class.

Figure 2 shows the change in the percentage of dissatisfied respondents at the end of the class in relation to their perception at the beginning of the class. In Tests 1 and 2, the indoor temperature changed only slightly even though air conditioning was on. However, the percentage of dissatisfied respondents at the end of the class was higher than at the beginning.

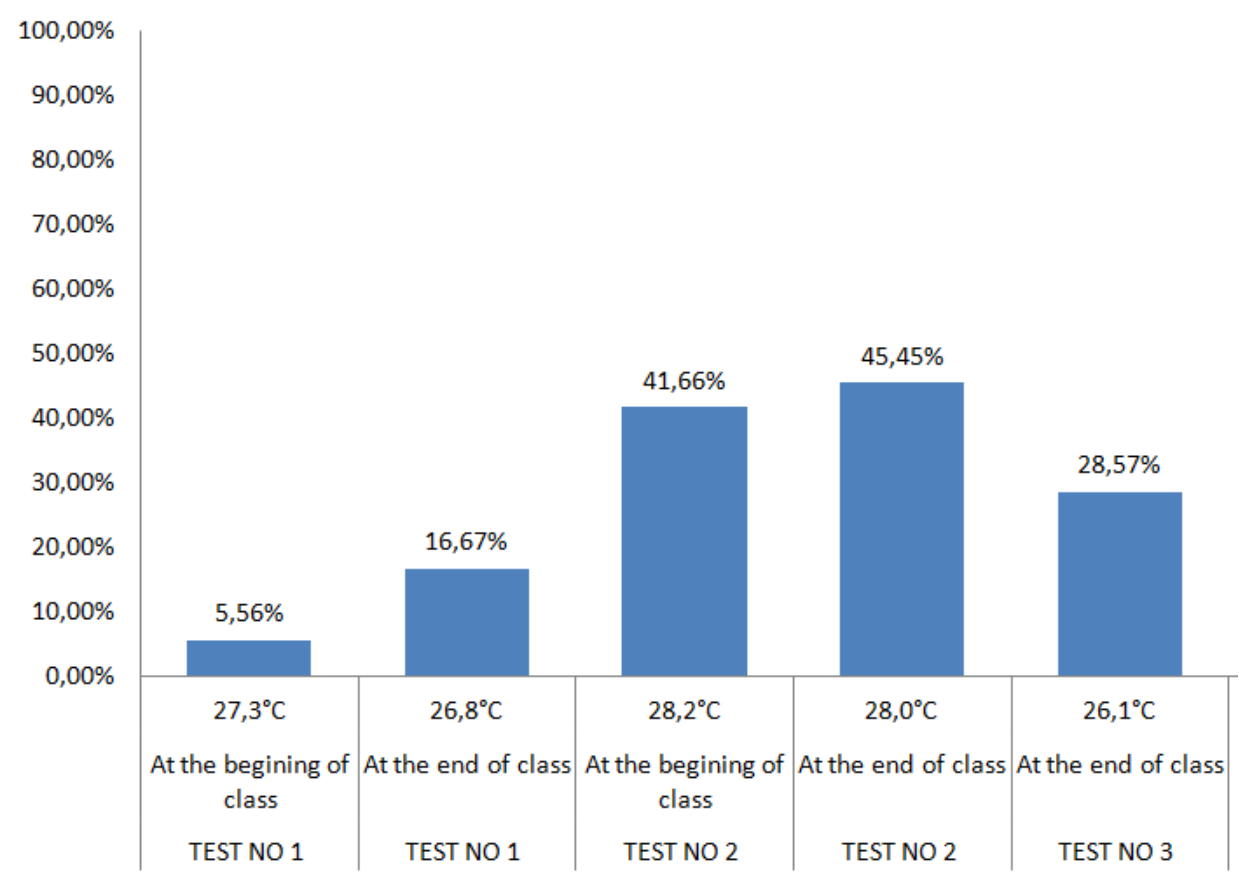

- Actual percentage of dissatisfied people

Fig. 2: Real percentage of respondents dissatisfied with their thermal sensations at the beginning and end of class.

Figure 3 compares the predicted mean vote PMV calculated according to ASHRAE-55-2013 and EN-15251 with the average perception recorded during the tests. It follows from Fig. 3 that in most cases, the real average perception is noticeably lower than that obtained from the calculation of the predicted values performed to the requirements of the currently binding standards. Only in one test, the real average perception was similar to that predicted average (PMV). 


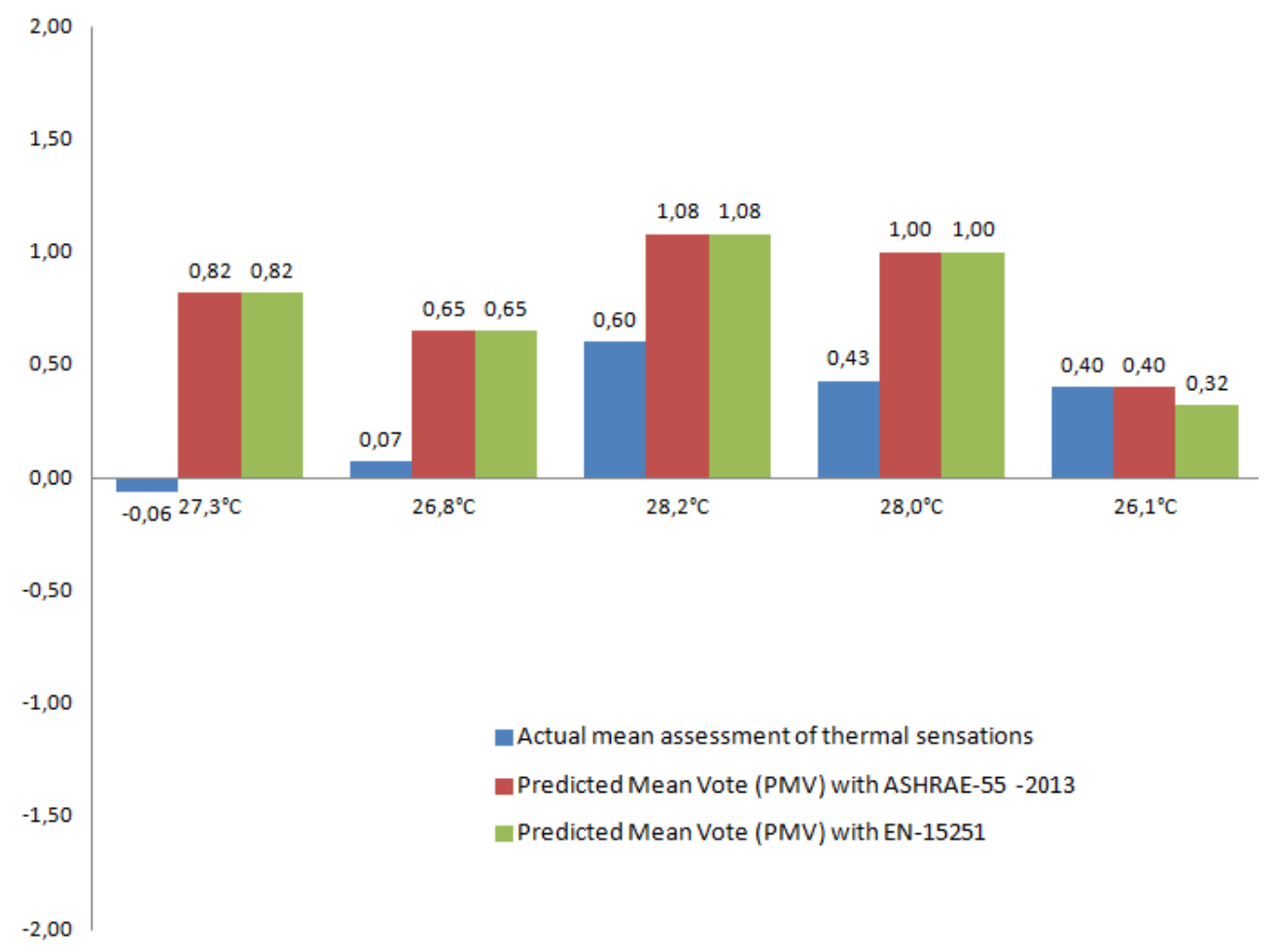

Fig. 3: The ambient temperature-dependent PMV according to ASHRAE-55-2013 and EN-15251 versus real average assessment of thermal sensations.

Figure 4 compares the PPD index calculated according to ASHRAE-55-2013 and EN-15251 with the real percentage of dissatisfied respondents. In most cases, the real percentage of dissatisfied respondents was higher than that calculated as the PPD index according to American and European standards.

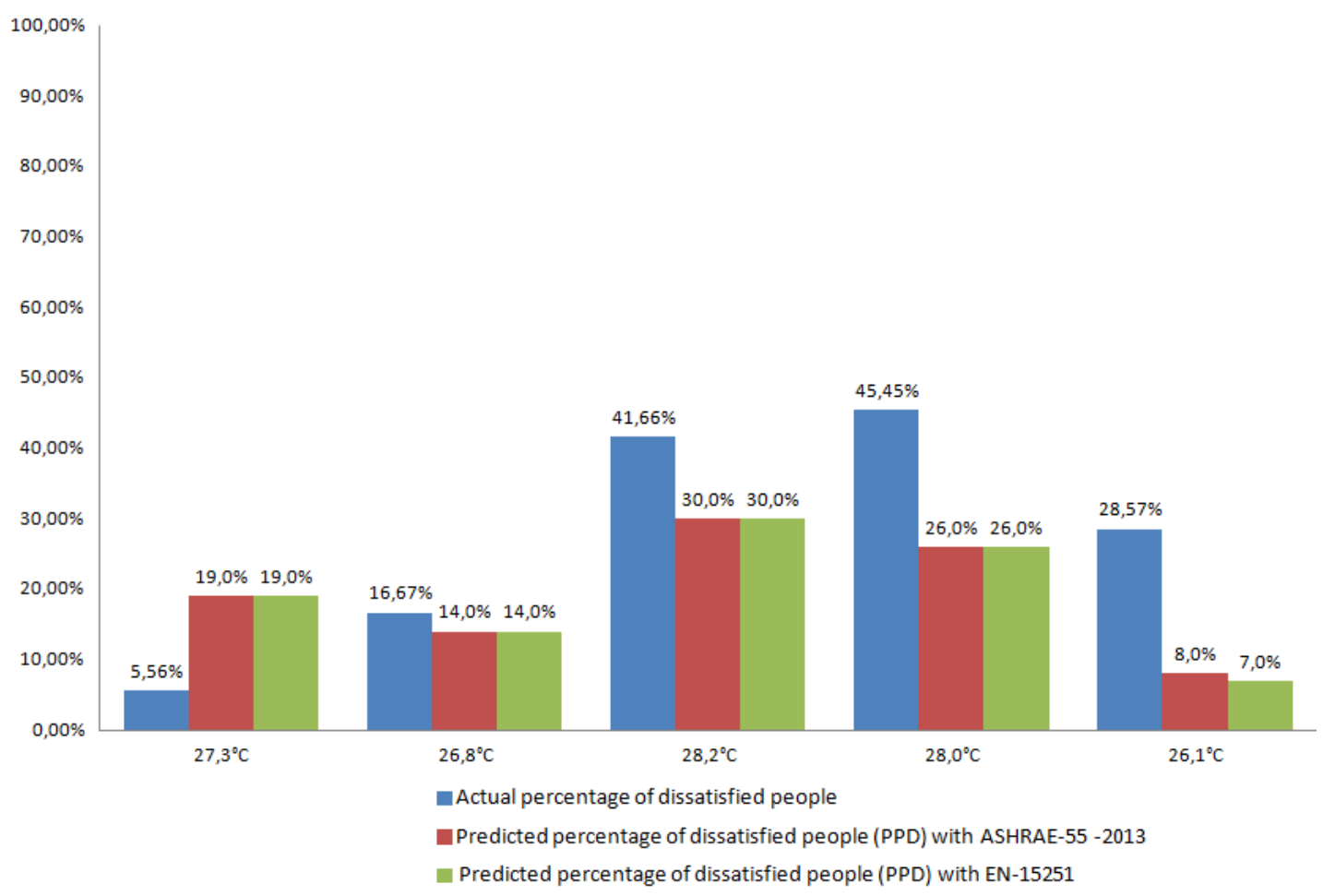

Fig. 4: The ambient temperature-dependent PPD according to ASHRAE-55-2013 and EN-15251 versus the actual percentage of dissatisfied respondents. 


\section{Conclusions}

Despite high technology of the intelligent building under analysis, the percentage of respondents dissatisfied with the thermal performance of the building was high. The data obtained indicate that the percentage of dissatisfied respondents increased at the end of classes despite the slightly lower air temperature. Also, noticeable differences were observed between the predicted and the real values of thermal comfort recorded by the respondents. The temperature change data combined with the questionnaire survey results and other indoor air parameters can be used to improve control systems operating in intelligent buildings. It seems therefore appropriate to modify the thermal perception indices for buildings and develop guidelines on controlling the HVAC systems operation to ensure optimal thermal conditions.

\section{References}

[1] BEDFORD, T.: The warmth factor in comfort at work: a physiological study of heating and ventilation. Industrial Health Research Board No. 76, HMSO, London, 1936.

[2] WINSLOW, C-E.A - HERRINGTON, L.P - GAGGE, A.P: Physiological reaction of the human body to various atmospheric humidity. Contribution No.16 from the John B. Pierce Laboratory of Hygiene, New Haven, 1937, pp. $288-299$.

[3] FANGER, P.O.: Calculations of thermal comfort: introduction of a basic comfort equation. ASHRAE Trans 73:1 - 4, 1967.

[4] FANGER, P.O.: Thermal comfort - analysis and applications in environmental engineering. Danish Technical Press, Copenhagen, 1970.

[5] EN ISO 7730, 2005. Ergonomics of the thermal environment - Analytical determination and interpretation of thermal comfort using calculation of the PMV and PPD indices and local thermal comfort criteria, International Standardisation Organisation, Geneva, 2005.

[6] PN-EN 15251, 2007. Indoor Environmental input parameters for design and assessment of energy performance of buildings addressing indoor air quality, thermal environment, lighting and acoustics, International Standardisation Organisation, Geneva, 2007.

[7] ASHRAE Standard 55-2013 Thermal Environmental Conditions for Human Occupancy. American Society of Heating, Refrigeration and Air Conditioning Engineers, 2013.

[8] ŚLIWOWSKI, L.: Interior microclimate and thermal comfort of human beings in rooms, Oficyna Wydawnicza Politechniki Wrocławskiej, Wrocław, 1999 (in Polish).

[9] KLINKE, T. - KRYGIER, K. - SEWERYNIAK, J.: Heating, Ventilation, Air Conditioning. Wydawnictwo Szkolne i Pedagogiczne, Warszawa, 1991 (in Polish).

[10]MAJEWSKI, G. - TELEJKO, M.: Thermal comfort in intelligent buildings, Structure and Environment, No. 1/2016, Vol. 8, 2016, p. 27. 